\title{
Transition from childhood to adulthood in Duchenne muscular dystrophy (DMD)
}

\author{
Sunil Rodger ${ }^{1 *}$, Birgit F Steffensen ${ }^{2}$, Hanns Lochmüller ${ }^{1}$ \\ From 6th European Conference on Rare Diseases and Orphan Products \\ Brussels, Belgium. 23-25 May 2012
}

Duchenne muscular dystrophy (DMD) is the most common childhood muscular dystrophy, affecting 1 in 3500 live male births. Mutations in the X chromosome result in an absence of dystrophin, causing progressive muscle degeneration and loss of ambulation by the early teens with respiratory, orthopaedic and cardiac complications. Without intervention these complications lead to death at a mean age of 19 years. However, the natural history of DMD is well-known and can be changed with proactive multidisciplinary management to address predictable complications[1]. Better care has led to a growing adult DMD population, challenging the notion of DMD as a "paediatric" disease. This population faces particular challenges, not only medical (e.g. associated with longterm steroid usage, orthopaedic, ventilation, and cardiac, gastrointestinal or genitourinary problems), but those associated with wider issues of transition. These include medical transfer from paediatric to adult services, and social transition to independent living and full societal inclusion.

Transfer arrangements to adult facilities, which vary considerably between clinics and countries, are usually needed due to regulations governing access to paediatric services. As DMD requires co-ordinated care, this move from cohesive paediatric clinics to disjointed adult services is often problematic, and a successful transfer should be the culmination of a period of planned transition. Wider social transition, enabling independent living and further education/employment, is also very important[2]. However, as with many other disabilities, adults with DMD face obstacles to full participation. Planning is crucial, and preparation for adulthood should be considered in

\footnotetext{
'TREAT-NMD, Institute of Genetic Medicine, Newcastle University, International Centre for Life, Central Parkway, Newcastle upon Tyne, NE1 3BZ, UK

Full list of author information is available at the end of the article
}

partnership with families as part of a comprehensive package of psychosocial care from diagnosis.

Recent research suggests that despite legal and health frameworks, DMD transition care in the UK is highly diverse and sometimes lacking[3]. Positive experiences were characterised by forward planning and long-standing relationships between the family and healthcare professionals. In Denmark an integrated model of care is provided by the National Rehabilitation Centre for NMDs (RCfM), which supports families from diagnosis with a comprehensive programme of courses and interventions at significant life milestones[4]. Patient advocacy groups also play a very important role in transition, particularly through programmes such as the MDA Transitions Center.

Although there is no one-size-fits-all model for DMD transition care, some features seem particularly important to successful transitions. These include continuity and stability in care; the integration of wider social issues; the involvement of the young man and his family in decisionmaking; and the support of patient advocacy groups.

\section{Acknowledgements}

The CARE-NMD project (http://www.care-nmd.eu) and TREAT-NMD Alliance (http://www.treat-nmd.eu).

\section{Author details}

${ }^{1}$ TREAT-NMD, Institute of Genetic Medicine, Newcastle University, International Centre for Life, Central Parkway, Newcastle upon Tyne, NE1 3BZ, UK. ${ }^{2}$ RehabiliteringsCenter for Muskelsvind, Neuromuscular Department, Kongsvang Allé 23, DK-8200 Århus, Denmark.

\section{Published: 22 November 2012}

\section{References}

1. Bushby K, Finkel R, Birnkrant D, Case L, Clemens P, Cripe L, Kaul A, Kinnett K, McDonald C, Pandya S, et al: Diagnosis and management of Duchenne muscular dystrophy, part 1: diagnosis, and pharmacological and psychosocial management. Lancet Neurology 2010, 9:77-93, Diagnosis and management of Duchenne muscular dystrophy, part 2: implementation of multidisciplinary care. Lancet Neurology 2010 9:177-189.
C Biomed Central

C 2012 Rodger et al; licensee BioMed Central Ltd. This is an Open Access article distributed under the terms of the Creative Commons Attribution License (http://creativecommons.org/licenses/by/2.0), which permits unrestricted use, distribution, and reproduction in any medium, provided the original work is properly cited. 
2. Beresford B: On the road to nowhere? Young disabled people and transition. Child: Care, Health and Development 2004, 30:581-587.

3. Abbot D, Carpenter J, Bushby K: Transition to adulthood for young men with Duchenne muscular dystrophy: research from the UK.

Neuromuscular Disorders 2012, 22:445-446.

4. Rahbek J, Werge B, Madsen A, Marquardt J, Steffensen BF, Jeppesen J: Adult life with Duchenne muscular dystrophy: observations among an emerging and unforeseen patient population. Paediatric Rehabiliation 2005, 8:17-28.

5. MDA Transitions Center. [http://transitions.mda.org].

doi:10.1186/1750-1172-7-S2-A8

Cite this article as: Rodger et al:: Transition from childhood to

adulthood in Duchenne muscular dystrophy (DMD). Orphanet Journal of Rare Diseases 2012 7(Suppl 2):A8.

Submit your next manuscript to BioMed Central and take full advantage of:

- Convenient online submission

- Thorough peer review

- No space constraints or color figure charges

- Immediate publication on acceptance

- Inclusion in PubMed, CAS, Scopus and Google Scholar

- Research which is freely available for redistribution

Submit your manuscript at www.biomedcentral.com/submit 